\title{
Infectious Meningitis and Encephalitis
}

\author{
Amanda L. Piquet, MD ${ }^{1}$ Jennifer L. Lyons, $\mathrm{MD}^{2,3}$ \\ ${ }^{1}$ Division of Neuroimmunology, Department of Neurology, University \\ of Utah Hospital, Salt Lake City, Utah \\ 2 Division of Neurological Infections and Inflammatory Diseases, \\ Department of Neurology, Brigham and Women's Hospital, \\ Boston, Massachusetts \\ ${ }^{3}$ Harvard Medical School, Boston, Massachusetts
}

Address for correspondence Jennifer L. Lyons, MD, Division of Neurological Infections and Inflammatory Diseases, Department of Neurology, Brigham and Women's Hospital, Boston, MA 02115 (e-mail: jlyons5@partners.org).

Semin Neurol 2016;36:367-372.
Abstract
Keywords
- encephalitis
- meningitis
- herpes simplex virus
- arbovirus

The clinician who is evaluating a patient with a suspected central nervous system infection often faces a large differential diagnosis. There are several signs, symptoms, geographical clues, and diagnostic testing, such as cerebrospinal fluid abnormalities and magnetic resonance imaging abnormalities, which can be helpful in identifying the etiological agent. By taking a systematic approach, one can often identify lifethreatening, common, and/or treatable etiologies. Here the authors describe some of the pearls and pitfalls in diagnosing and treating acute infectious meningitis and encephalitis.

\section{Encephalitis}

\section{Clinical Presentation}

It is important to identify the clinical differences between encephalitis and encephalopathy. Encephalitis is a pathologic diagnosis, but the International Encephalitis Consortium ${ }^{1}$ has defined clinical criteria to assist with bedside diagnosis. These are inclusion of the major criteria of altered mental status (defined as altered level of consciousness, lethargy, or personality change) and at least 2 of the following minor criteria: fever ( $>38^{\circ} \mathrm{C}$ within 72 hours of presentation), seizure not attributable to preexisting seizure disorder, new focal neurological deficit, cerebrospinal fluid (CSF) pleocytosis, and imaging and/or electroencephalography consistent with encephalitis. ${ }^{1}$ Encephalopathy, on the other hand, is the clinical term for a confusional state without localizable neurologic deficit. Encephalopathy does not imply an etiology, and although it can be due to an organic brain disease, often it is secondary to a systemic illness.

Not all encephalitides are infectious; however, viruses are the most commonly identified cause of acute encephalitis. Overall, there are more than 100 pathogens capable of causing encephalitis. Further, even in primary infectious encephalitis, there may be a robust inflammatory response seen in the central nervous system (CNS), thus justifying the concomitant use of corticosteroids in the setting of properly treating the infection. This is discussed further in the Treatment section below.

Herpes simplex virus (HSV) is the most commonly identified etiology of viral encephalitis in developed countries. Ninety percent of herpes simplex virus encephalitis (HSVE) is caused by HSV-1. It has a bimodal age distribution of $<20$ years old and $>50$ years old. ${ }^{2}$ Immunosuppression is not a risk factor for HSVE, and it does not have a seasonal predilection. Clinically, HSVE presents with symptoms of fever (90\%), headache (81\%), personality change (71\%), and/or seizures (67\%).

If patients with recent HSVE present with relapsing symptoms a few weeks (typically 4-6 weeks) after a complete 14- to 21-day course of treatment with acyclovir, one should consider an immunomediated disorder with $\mathrm{N}$-methyl-D-aspartate receptor (NMDAR) antibodies if there are no overt signs of true viral relapse. Studies suggest that HSVE can trigger antiNMDAR encephalitis. ${ }^{5,6}$

Arbovirus encephalitides are rare in the United States and are very much region- and season-dependent (see - Table $\mathbf{1}$ ). The majority of arbovirus infections are asymptomatic, making serum IgG positivity at times misleading in the incorrect context. When encephalitis does occur it is typically preceded by an influenza-like prodrome followed by a headache, altered level of consciousness, seizures, and focal neurologic
Issue Theme Pearls and Pitfalls, Part 1; Guest Editors, Justin C. McArthur, MBBS, MPH, FAAN, FANA, and Nicoline Schiess, $\mathrm{MD}, \mathrm{MPH}$
DOI http://dx.doi.org/ 10.1055/s-0036-1585099. ISSN 0271-8235. 
Table 1 Epidemiology and clinical presentation of different arboviruses

\begin{tabular}{|c|c|c|}
\hline Arbovirus & Epidemiology & Clinical features and presentation \\
\hline \multicolumn{3}{|l|}{ Mosquito vector } \\
\hline Banna virus & Asia; rare & $\begin{array}{l}\text { Flu-like symptoms, encephalitis; often misdiag- } \\
\text { nosed as JEV }\end{array}$ \\
\hline Dengue virus & $\begin{array}{l}\text { South America, Central America, Mexico, } \\
\text { Sub-Saharan Africa, South-East Asia, and Western } \\
\text { Pacific }\end{array}$ & $\begin{array}{l}\text { Encephalitis or encephalopathy; fever, arthralgias, } \\
\text { headache, petechiae and other hemorrhagic } \\
\text { manifestations }\end{array}$ \\
\hline $\begin{array}{l}\text { Eastern equine } \\
\text { encephalitis virus }\end{array}$ & $\begin{array}{l}\text { Eastern U.S.; mainly along the Gulf coast, eastern } \\
\text { seaboard, and Great Lakes }\end{array}$ & $\begin{array}{l}\text { Most infection is subclinical, but can cause fulmi- } \\
\text { nant encephalitis with focal signs (cranial nerve } \\
\text { palsies, seizures); mortality } 30 \% \text { with neurologic } \\
\text { sequelae in most survivors }\end{array}$ \\
\hline Chikungunya virus & $\begin{array}{l}\text { North America, Central, South America, Africa, } \\
\text { South-East Asia, and Western Pacific }\end{array}$ & $\begin{array}{l}\text { Rarely causes meningitis and/or encephalitis; high } \\
\text { fevers, arthralgias }\end{array}$ \\
\hline Jamestown Canyon virus & $\begin{array}{l}\text { Canada, Alaska, and northern U.S. states; sporadic } \\
\text { cases }\end{array}$ & Encephalitis, meningitis \\
\hline Japanese encephalitis virus & $\begin{array}{l}\text { Most common causes of worldwide epidemic } \\
\text { encephalitis; Asia }\end{array}$ & $\begin{array}{l}\text { Seizures, extrapyramidal features, rhombence- } \\
\text { phalitis or poliomyelitis-like syndrome; mortality } \\
20-30 \%\end{array}$ \\
\hline La Crosse & $\begin{array}{l}\text { Midwestern and eastern U.S.; highest incidence } \\
\text { along Appalachian range }\end{array}$ & Seizure, hyponatremia, focal weakness/paralysis \\
\hline $\begin{array}{l}\text { Murray Valley } \\
\text { encephalitis virus }\end{array}$ & Australia and New Guinea & $\begin{array}{l}\text { Seizures, somnolence, similar to JEV; mortality } \\
\text { 30\%; mostly affects children }\end{array}$ \\
\hline Rocio virus & Brazil; typically part of an epidemic outbreak & Severe encephalitis; high mortality rate \\
\hline Snowshoe hare virus & Canada, northern U.S., and eastern Asia & Encephalitis, meningitis; mild \\
\hline St. Louis encephalitis & $\begin{array}{l}\text { Americas with a geographical range of Canada to } \\
\text { Argentina; however, most cases in eastern and } \\
\text { central U.S.; 2nd most common epidemic cause } \\
\text { in U.S. after WNV }\end{array}$ & $\begin{array}{l}\text { Tremors, seizures, focal signs, may cause extra- } \\
\text { pyramidal or cerebellar syndrome, hyponatremia, } \\
\text { bladder dysfunction; mortality } 20 \% \text { in elderly }\end{array}$ \\
\hline Tahyna & Europe and Asia & Encephalitis \\
\hline $\begin{array}{l}\text { Venezuelan equine } \\
\text { encephalitis virus }\end{array}$ & $\begin{array}{l}\text { Florida and southwestern U.S., Central and South } \\
\text { America }\end{array}$ & $\begin{array}{l}\text { Flu-like syndrome with myalgias, mild encephalitis; } \\
\text { children more than adults }\end{array}$ \\
\hline $\begin{array}{l}\text { Western equine } \\
\text { encephalitis virus }\end{array}$ & $\begin{array}{l}\text { West of Mississippi in the U.S. and Central and } \\
\text { South America; rare }\end{array}$ & $\begin{array}{l}\text { Encephalitis; mortality }<5 \% \text {; young children and } \\
\text { older adults }\end{array}$ \\
\hline West Nile virus & $\begin{array}{l}\text { North and central America, Africa, Asia, Middle } \\
\text { East, and southern Europe }\end{array}$ & $\begin{array}{l}\text { Meningoencephalitis, tremors, myoclonus, may } \\
\text { have extrapyramidal syndrome and/or poliomy- } \\
\text { elitis-like syndrome }\end{array}$ \\
\hline \multicolumn{3}{|l|}{ Tick-borne vector } \\
\hline Colorado tick fever virus & $\begin{array}{l}\text { Rocky Mountain region of U.S. (reported in } \\
\text { Arizona, Colorado, Montana, Oregon, Utah, and } \\
\text { Wyoming); rare }\end{array}$ & $\begin{array}{l}\text { Fever, headaches, retro-orbital pain, myalgias, } \\
\text { abdominal pain, malaise, meningitis, encephalitis; } \\
\text { most severe infections in children, rare }\end{array}$ \\
\hline Eyach virus & Eastern Europe, France and Germany; rare & Meningitis, encephalitis, polyradiculoneuritis \\
\hline Kemerovo virus & Eastern Europe and Russia & Meningitis, encephalitis, polyradiculitis; rare \\
\hline Kyasanur forest disease virus & India & Early hemorrhagic fever with late encephalitis \\
\hline Louping-ill virus & England, Scotland, and Ireland & Encephalitis \\
\hline Negishi virus & Japan & Encephalitis \\
\hline Powassan virus & $\begin{array}{l}\text { Canada and northeast region of the U.S. and Great } \\
\text { Lake states }\end{array}$ & Encephalitis, mortality 5-10\% \\
\hline Tick-borne encephalitis & Europe, Eastern Russia, and Asia & $\begin{array}{l}\text { Nonspecific prodrome, occasionally poliomyelitis- } \\
\text { like syndrome; low mortality }\end{array}$ \\
\hline \multicolumn{3}{|l|}{ Sandfly vector } \\
\hline Toscana virus & Mediterranean region (especially Italy) & Meningitis, encephalitis \\
\hline
\end{tabular}

Abbreviations: JEV, Japanese encephalitis virus; U.S., United States; WNV, West Nile virus.

Source: Data from Cho TA, Mckendall RR, 2014 ${ }^{15}$; Tunkel et al, $2008^{25}$, and CDC.gov. ${ }^{26}$ 
deficits. West Nile virus (WNV) is the most common of the flaviviruses in the United States and has been reported from all 48 contiguous states, accounting for approximately $98 \%$ of arthropod-borne encephalitis. ${ }^{7}$ West Nile virus, along with other flaviviruses throughout the world such as the St. Louis encephalitis virus, Japanese encephalitis virus, Powassan, and tick-borne encephalitis virus, can be associated with parkinsonism, tremor, and myoclonus. Patients with WNV can also present with a myelitis-like syndrome with acute flaccid paralysis. The flaviviruses in the United States, with the exception of Powassan (which is tick-borne), are transmitted by mosquitoes.

\section{Diagnostic Work-Up}

Herpes simplex virus polymerase chain reaction (PCR) from the CSF is $98 \%$ sensitive and $94 \%$ specific for HSVE. ${ }^{8}$ However, it can be negative early in the disease. If the PCR is negative and suspicion is high, repeat the test and/or complete a course of treatment. The optimal time for PCR positivity in untreated HSV disease is 2 to 10 days after symptom onset. ${ }^{2}$ It is unknown how soon after starting acyclovir the sensitivity of the PCR declines, but some studies have suggested the sensitivity remains high for 5 to 7 days. ${ }^{8-10}$ However, caution should be used when interpreting these results because vidarabine was used rather than acyclovir in most of these cases.

Several arboviruses can cause encephalitis and vary widely in epidemiology; however, most have a seasonal prevalence limited to the summertime. Diagnostic testing should be based on geographic location and travel history. For most arboviruses, serologic testing of serum and CSF is preferred to PCR. This is because measurable viral replication typically occurs prior to the symptom onset. ${ }^{1}$ For example, in patients with WNV, CSF PCR is approximately $57 \%$ sensitive for neuroinvasive disease. ${ }^{1,11}$ That said, in the very acute infection window, the PCR may still be positive and the IgM may be negative. The percentage of seropositive patients increases by approximately $10 \% / d$ during the first week of illness. ${ }^{11,12}$ If the suspicion for disease is strong in those patients with initial negative serology results, repeat testing is recommended.

Diagnostic testing for cytomegalovirus (CMV) and Epstein-Barr virus (EBV) on the CSF of an adult is usually unnecessary unless the patient is severely immunocompromised. Testing for such can sometimes cloud the picture, as positive results may not indicate active disease. Furthermore, the neurologic complications of acute systemic CMV and/or EBV infection are often entirely immunomediated.

Always remember serum testing early in the diagnostic workup. All patients should have blood cultures sent, and human immunodeficiency virus (HIV) testing should be performed as well because this will substantially change the differential diagnosis.

Newer diagnostic techniques include approaches with next-generation sequencing on spinal fluid. Unbiased nextgeneration sequencing is not yet commercially available; this approach still needs validation. However, there have been case reports of successful pathogen detection using this technique in undiagnosed infectious encephalitis. Examples include astrovirus in an immunocompromised boy ${ }^{13}$ and neuroleptospirosis in a young boy with severe combined immunodeficiency. ${ }^{14}$

Magnetic resonance imaging (MRI) is often a very useful tool in encephalitis and certain findings can help identify potential etiologies (see - Fig. 1):

- For HSVE, the MRI most classically has unilateral or asymmetrical T2/ fluid-attenuated inversion-recovery (FLAIR) hyperintensities in the mesial temporal lobes. However, HSV is not limited to this MRI finding and has many atypical presentations. Therefore, it is advisable not to rule out HSV based solely on imaging.

- Magnetic resonance imaging in WNV can be highly variable with findings ranging from normal to T2 hyperintense lesions in the deep gray matter and brainstem, lesions in the lobar structures, or even leptomeningeal disease. Additionally, spinal MRI may be useful in the setting of acute flaccid limb weakness given WNV has tropism for anterior horn cells resulting in a poliomyelitis-like syndrome.

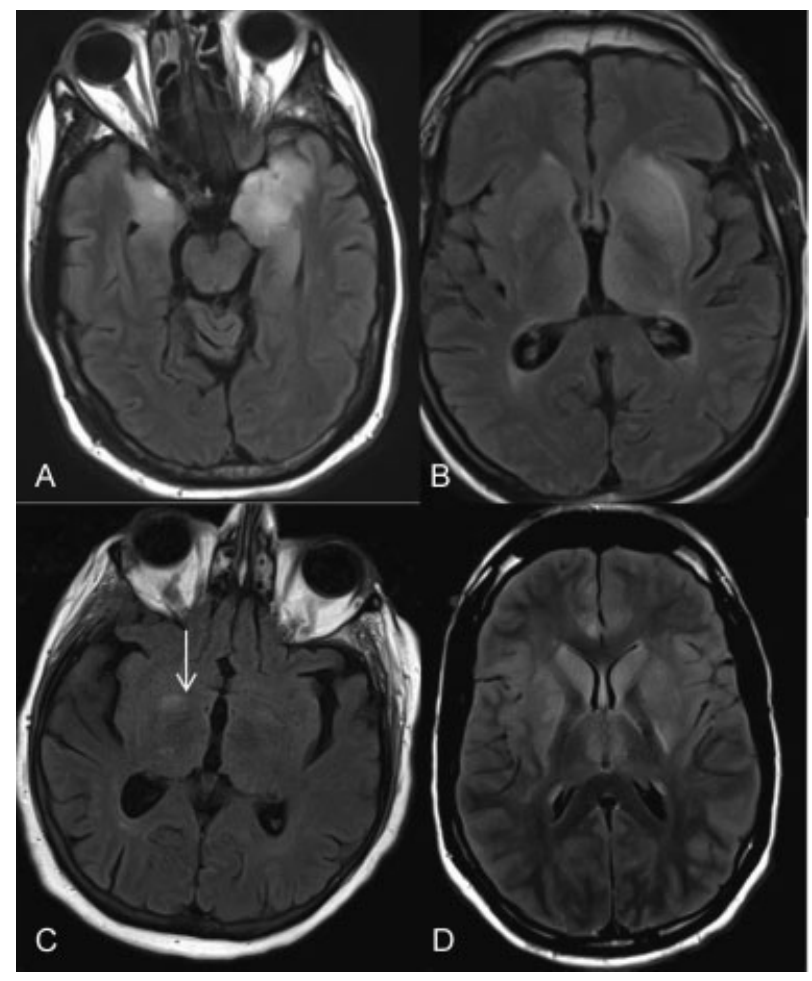

Fig. 1 Magnetic resonance images of various infectious encephalitides. (A) Patient with herpes simplex virus encephalitis. Asymmetric T2/ fluid-attenuated inversion-recovery (FLAIR) hyperintensities and edema involving the bilateral mesial temporal lobes are seen. (B) Patient with eastern equine encephalitis virus. Abnormal T2/FLAIR hyperintensities of the bilateral basal ganglia and thalami, left greater than right are seen. Additionally, there is T2 prolongation in the midbrain and mesial temporal lobes (not shown here). (C) Patient with West Nile virus encephalitis. There is a small area of T2/FLAIR hyperintensity in the right basal ganglia (white arrow). (D) Patient with Powassan encephalitis. Seen are T2/FLAIR hyperintensities involving the bilateral insula, opercula, perisylvian temporal lobes, medial thalami, caudate nuclei, and putamina. 
- Brainstem involvement, or rhombencephalitis, may be seen on MRI scans with HSV, WNV, enterovirus, and Listeria monocytogenes, and can also be autoimmune. ${ }^{15}$

- Ischemic and hemorrhagic changes can be seen in varicella-zoster virus (VZV), HSV, infectious endocarditis, syphilis, tuberculosis, and fungal meningitis.

- Petechial or microhemorrhages can be seen with many infections; they can help to determine the risk of anticoagulation and/or antiplatelets when such therapies are being considered. Always obtain gradient echo or susceptibility-weighted imaging when obtaining MRIs.

\section{Treatment}

Some encephalitides are entirely immunomediated and not necessarily of infectious etiology. However, the most severe infectious encephalitides often have a significant component of immunomediated destruction; therefore, corticosteroids can help mitigate damage and/or mass effect. It is important to recognize that corticosteroids can worsen certain infectious conditions (fungal, tuberculotic, or parasitic) if they are not being treated concomitantly. Always consider geographical location/travel history before initiating a steroid trial. For example, in patients who migrate from places endemic to tuberculosis and Strongyloides, reactivation of occult infection is possible with corticosteroids, so their use should be avoided.

For HSVE, it is recommended to treat with acyclovir for 14 to 21 days to reduce disease recurrence; early recommendations for only 10 days of treatment have long fallen out of favor due to reports of relapse. Renal function must be monitored closely while on acyclovir, and prophylactic hydration is recommended. Steroids have also been suggested for treatment in HSVE given the strong inflammatory cascade and immune response seen with the infection. Case reports of concomitant or delayed administration of corticosteroids compared with acyclovir alone have showed favorable outcomes, ${ }^{16}$ and a randomized trial evaluating their timing and utility is underway (German Trial of Acyclovir and Corticosteroids in Herpes-Simplex-Virus-Encephalitis [GACHE]). ${ }^{17}$

\section{Meningitis}

\section{Clinical Presentation}

Clinical signs of meningitis include fever, headache, nuchal rigidity, and vomiting with or without photophobia, but not all patients present with all of the cardinal signs and symptoms. It is important to recognize that approximately 95\% of patients with bacterial meningitis have altered mental status. ${ }^{18}$ Seizures may be a clue to differentiating meningitis versus encephalitis, as they are usually a late manifestation in meningitis, but not infrequently a presenting symptom of encephalitis, especially HSVE.

Prior to a lumbar puncture, patients should undergo computed tomography of the head if there are focal neurologic deficits, underlying immune compromise, a decreased level of consciousness, or papilledema. Symptoms of epidural abscess can rarely look like meningitis, and so if there are any red flags (such as back pain or cauda equina syndrome), then one needs to be cautious before performing a lumbar puncture, and the patient may require further imaging for investigation.

When neuroinvasive, Listeria monocytogenes can present as meningitis, encephalitis, abscess, or ventriculitis, resulting in hydrocephalus. Rhombencephalitis typically presents as a biphasic illness with a prodrome of fever, headache, and nausea followed by focal deficits (cranial neuropathies, pyramidal tract weakness, ataxia, and brainstem findings). Listeria meningitis and encephalitis can occur in an immunocompetent individual without clear predisposing factors. However, particular conditions such as $<1$ month of age, $>50$ years of age, underlying malignancy, and pregnancy place individuals at higher risk.

Rashes associated with meningitis and meningoencephalitis include

- Rocky Mountain spotted fever is associated with a rash of $<1 \mathrm{~cm}$ erythematous macules that begins on the wrists and ankles and subsequently spreads centrally to involve the trunk and face. ${ }^{19}$ Petechial lesions around the axilla, palms of the hands, and soles of feet are characteristic.

- Other infections that may present with lesions on the palms and soles include meningococcemia and syphilis. The rash seen with meningococcemia begins with petechial lesions on the trunk and lower extremities and progresses to involve the mucous membranes and conjunctiva. These disseminated lesions can become gangrenous.

- Patients with VZV meningitis or encephalitis may have a history of shingles in the past several months, but if they do not, it does not exclude the possibility of VZV.

- An erythematous rash on the trunk can be seen with enterovirus and WNV.

\section{Diagnostic Work-Up}

Listeria has been reported with normal CSF cell counts, and the Gram stain may not show bacteria. Cerebrospinal fluid culture is positive in approximately $40 \%$ of patients with listeriosis. ${ }^{4}$ Blood cultures can be helpful if drawn before the initiation of antibiotics. Even though antibody titers are typically unreliable in the acute phase, they can be used later in culture-negative cases in patients treated empirically.

Viral meningitis may present with a predominance of polymorphonuclear leukocytes in the CSF with a transition to a lymphocytic pleocytosis over 24 hours. As enteroviral infections are a common cause of viral meningitis, they should be at least considered during the diagnostic workup. If the enterovirus PCR is positive and the CSF culture is negative for 48 hours, antibiotics may be discontinued. Additionally, if the clinical suspicion is low for HSVE and the HSV PCR is negative in the setting of a positive enterovirus PCR, acyclovir may also be discontinued. ${ }^{20}$ This may avoid prolonged exposure to unnecessary antimicrobial medications.

As in the diagnostic work-up for encephalitis, early serum testing with blood cultures (ideally before the initiation of antibiotics) and for HIV should be performed. 
Some so-called chronic meningitides can in fact have a rather sudden onset, so low glucose in the CSF of an acutely ill patient may not mean bacterial meningitis. Cerebrospinal fluid glucose is typically mildly decreased in tuberculous meningitis at approximately 35 to $40 \mathrm{mg} / \mathrm{dL}^{21}$

Herpes simplex virus- 2 is the most common cause of chronic or recurrent meningitis. Although this designation is for recurrent bouts of lymphocytic CSF pleocytosis with HSV DNA detection, the literature on this entity sometimes include cases with HSV PCR negative pleocytosis and/or no lumbar puncture data at all, making the epidemiology difficult to determine. As many patients with a history of meningitis also have migraine whose symptoms can mimic meningitis, it is important to make this diagnostic distinction so as not to overtreat more mundane etiologies of headache in these patients.

A note on vaccines: The routine (as of 2015) meningococcal vaccine does not cover serogroup $B$, which causes up to one-third of cases of meningococcal meningitis in the United States; therefore, vaccination does not rule out meningococcal disease. Additionally, although pneumococcal vaccines tend to prevent more severe forms of the bacteria, with 90 known subtypes, vaccination does not altogether prevent meningitis by Streptococcus pneumoniae as well. ${ }^{22}$

\section{Treatment}

It is imperative to start treatment with antibiotics immediately if bacterial meningitis is suspected. Once antibiotics are initiated, after 4to 12 hours the organism may be absent in CSF culture; however, pleocytosis and protein elevation will persist.

Adjunctive treatment with dexamethasone should be initiated early (before the first dose of antibiotics) in bacterial meningitis in developed countries. However, it is most useful in pneumococcal meningitis and discontinuation of the steroids should be considered based on the results of the CSF Gram stain and culture. ${ }^{23}$

Recurrent meningitis is most often caused by HSV-2 when an agent is found. However, the literature varies widely regarding the recommendations for treatment and/or prophylactic antiviral therapy. The most recent literature has not supported the use of prophylactic medication. $^{24}$

\section{Conclusion}

Infectious meningitis and encephalitis carry significant associated morbidity and mortality. The diagnosis of both meningitis and encephalitis can be quite challenging because there are several etiologies, including infectious and noninfectious. Unfortunately, many cases remain undiagnosed. Future diagnostics including next-generation sequencing show promise in the diagnosis of CNS infections. However, with careful clinical investigation and knowing the diagnostic pearls and pitfalls, one can often identify life-threatening, common, and/ or treatable etiologies.

\section{References}

1 Venkatesan A, Tunkel AR, Bloch KC, et al; International Encephalitis Consortium. Case definitions, diagnostic algorithms, and priorities in encephalitis: consensus statement of the international encephalitis consortium. Clin Infect Dis 2013;57(8):1114-1128

2 Steiner I. Herpes simplex virus encephalitis: new infection or reactivation? Curr Opin Neurol 2011;24(3):268-274

3 Whitley RJ, Soong SJ, Linneman C Jr, Liu C, Pazin G, Alford CA; Clinical Assessment. Herpes simplex encephalitis. JAMA 1982; 247(3):317-320

4 Bhattacharyya S, Lyons L. Neurology. Encephalitis. In: Singh AK, editor. Scientific American Medicine [online] Hamilton (ON): Decker Intellectual Properties; May 2015. DOI: 10.2310/ 7900.1203. http://www.sciammedicine.com. Accessed June 27, 2016.

5 Leypoldt F, Titulaer MJ, Aguilar E, et al. Herpes simplex virus-1 encephalitis can trigger anti-NMDA receptor encephalitis: case report. Neurology 2013;81(18):1637-1639

6 Armangue T, Leypoldt F, Málaga I, et al. Herpes simplex virus encephalitis is a trigger of brain autoimmunity. Ann Neurol 2014; 75(2):317-323

7 Tyler KL. Current developments in understanding of West Nile virus central nervous system disease. Curr Opin Neurol 2014; 27(3):342-348

8 Lakeman FD, Whitley RJ; National Institute of Allergy and Infectious Diseases Collaborative Antiviral Study Group. Diagnosis of herpes simplex encephalitis: application of polymerase chain reaction to cerebrospinal fluid from brain-biopsied patients and correlation with disease. J Infect Dis 1995;171(4):857-863

9 Sköldenberg B. Herpes simplex encephalitis. Scand J Infect Dis Suppl 1996;100:8-13

10 Debiasi RL, Tyler KL. Molecular methods for diagnosis of viral encephalitis. Clin Microbiol Rev 2004;17(4):903-925

11 Lanciotti RS, Kerst AJ, Nasci RS, et al. Rapid detection of West Nile virus from human clinical specimens, field-collected mosquitoes, and avian samples by a TaqMan reverse transcriptase-PCR assay. J Clin Microbiol 2000;38(11):4066-4071

12 Tardei G, Ruta S, Chitu V, Rossi C, Tsai TF, Cernescu C. Evaluation of immunoglobulin $M$ (IgM) and IgG enzyme immunoassays in serologic diagnosis of West Nile virus infection. J Clin Microbiol 2000;38(6):2232-2239

13 Schubert RD, Wilson MR. A tale of two approaches: how metagenomics and proteomics are shaping the future of encephalitis diagnostics. Curr Opin Neurol 2015;28(3):283-287

14 Wilson MR, Naccache SN, Samayoa E, et al. Actionable diagnosis of neuroleptospirosis by next-generation sequencing. $\mathrm{N}$ Engl J Med 2014;370(25):2408-2417

15 Cho TA, Mckendall RR. Clinical approach to the syndromes of viral encephalitis, myelitis, and meningitis. Handb Clin Neurol 2014; 123:89-121

16 Ramos-Estebanez C, Lizarraga KJ, Merenda A. A systematic review on the role of adjunctive corticosteroids in herpes simplex virus encephalitis: is timing critical for safety and efficacy? Antivir Ther 2014;19(2):133-139

17 Martinez-Torres F, Menon S, Pritsch M, et al; GACHE Investigators. Protocol for German trial of acyclovir and corticosteroids in herpes-simplex-virus-encephalitis (GACHE): a multicenter, multinational, randomized, double-blind, placebo-controlled German, Austrian and Dutch trial [ISRCTN45122933]. BMC Neurol 2008;8:40

18 van de Beek D, de Gans J, Spanjaard L, Weisfelt M, Reitsma JB, Vermeulen M. Clinical features and prognostic factors in adults with bacterial meningitis. N Engl J Med 2004;351(18): 1849-1859

19 Tsai J, Nagel MA, Gilden D. Skin rash in meningitis and meningoencephalitis. Neurology 2013;80(19):1808-1811 
20 Ramers C, Billman G, Hartin M, Ho S, Sawyer MH. Impact of a diagnostic cerebrospinal fluid enterovirus polymerase chain reaction test on patient management. JAMA 2000;283(20): 2680-2685

21 Roos KL. Pearls: infectious diseases. Semin Neurol 2010;30(1): $71-73$

22 Hsu HE, Shutt KA, Moore MR, et al. Effect of pneumococcal conjugate vaccine on pneumococcal meningitis. $\mathrm{N}$ Engl J Med 2009;360(3):244-256

23 Tunkel AR, Hartman BJ, Kaplan SL, et al. Practice guidelines for the management of bacterial meningitis. Clin Infect Dis 2004;39(9): $1267-1284$
24 Aurelius E, Franzen-Röhl E, Glimåker M, et al; HSV-2 Meningitis Study Group. Long-term valacyclovir suppressive treatment after herpes simplex virus type 2 meningitis: a double-blind, randomized controlled trial. Clin Infect Dis 2012;54(9): 1304-1313

25 Tunkel AR, Glaser CA, Bloch KC, et al; Infectious Diseases Society of America. The management of encephalitis: clinical practice guidelines by the Infectious Diseases Society of America. Clin Infect Dis 2008;47(3):303-327

26 Centers for Disease Control and Prevention. USA cumulative human disease cases reported to CDC ArboNET 2003-2015. http://diseasemaps.usgs.gov/index.html. Accessed June 22, 2016 